\title{
O(s) Prémio(s) da Crítica 2003
}

\section{Paulo Eduardo Carvalho}

Durante largos anos, uma das manifestações mais visíveis e regulares da Associação Portuguesa de Críticos de Teatro consistiu na atribuição anual de um conjunto de prémios, distribuídos pelas diversas modalidades de maior reconhecimento no domínio da criação teatral. Quando relançámos a nossa actividade, em início de 2003, foi opinião praticamente unânime dos antigos e novos membros da APCT que seria importante retomar essa iniciativa: porque nos continua a parecer pertinente destacar a qualidade diversa daquilo que, entre nós, se vai fazendo, mas também porque acreditámos que a essa distinção poderia corresponder uma oportunidade para se reflectir criticamente sobre a prática que a suscita.

São, contudo, muito diversas as coordenadas da criação teatral nestes primeiros anos do século XXI, quando comparadas com as dos anos oitenta e noventa do século passado. Ao mesmo tempo a que se assiste a uma multiplicação, diversificação e dispersão geográfica da criação teatral, deparamo-nos com uma inquietante retracção do espaço crítico, nas suas amplas valências de informação, análise, debate e avaliação. Considerámos, assim, não estarem reunidas as condições para regressar à atribuição de prémios por modalidades, sobretudo porque tal estratégia, de inequívoca legitimidade, parece sempre conduzida pela ambição discutivel de eleger o "melhor", ainda que no espaço de um ano ou temporada. Acabámos por optar pela criação de um único prémio - o Prémio da Crítica -, destinado a distinguir "uma invulgar contribuição para o panorama artístico nacional" no domínio das artes performativas. Mas porque antecipávamos a frustração induzida por esta espécie de modelo único, contemplámos no regulamento então aprovado a possibilidade de atribuição de Menções Especiais, até ao número máximo de três. 0 mesmo regulamento definiu ainda a nomeação anual de um júri de cinco pessoas, com a tarefa da decisão final, mas também com a responsabilidade de atender às sugestões que, oportunamente, os restantes associados Ihes fizessem chegar.

0 júri nomeado para o ano de 2003 traduziu o desejável rejuvenescimento desta Associação: Ana Pais, Miguel-Pedro Quadrio, Mónica Guerreiro, Rui Cintra e eu próprio. Decidiu este júri atribuir o Prémio da Crítica 2003 à tradutora e dramaturgista Vera San Payo de Lemos e, tirando o máximo partido das possibilidades concedidas pelo já referido regulamento, atribuir ainda três Menções Especiais: ao projecto Percursos, uma iniciativa do Centro de Pedagogia e Animação do Centro Cultural de Belém, coordenado por Madalena
Victorino e Giacomo Scalisi; ao espectáculo Circo, do Teatro da Garagem, com texto e encenação de Carlos J. Pessoa; e ao sonoplasta e desenhador de som Francisco Leal.

Se, por um lado, esta nova moldura de atribuição de prémios surgiu como a nossa resposta à referida fragmentação do tecido teatral português a nível produtivo e criativo e à consequente consciência da impossibilidade de um visionamento exaustivo da totalidade da criação teatral em todo o território nacional, por outro, ela trouxe consigo a possibilidade de acrescentar um novo tipo de sequência e "consequência" à nossa atenção crítica. Assim, no dia escolhido para a cerimónia da entrega pública dos humildes troféus oferecidos pela APCT - concebidos pelos mesmos criativos talentosos que asseguram o desenho gráfico desta revista -, esta Associação criou a oportunidade de presentear os distinguidos com um momento raro de partilha colectiva de um discurso mais desenvolvido e argumentado sobre o seu labor. Tratou-se, a um só tempo, de publicamente justificarmos as nossas conviç̧ões e, por outro, de contribuir, como julgamos ser nosso dever, para a ampliação "crítica" dos méritos reconhecidos aos premiados.

As contribuições que integram o dossiê temático deste primeiro número da nossa revista, Sinais de cena, correspondem, assim, aos textos que foram apresentados nessa cerimónia, realizada no passado dia 15 de Maio, às 18h, no espaço do Jardim de Inverno do Teatro Municipal de S. Luiz, por amável cedência do seu director, Jorge Salavisa, e cuidada atenção de Francisco Barbosa. Porque optámos por não "pré-formatar" excessivamente estas intervenções, cada um dos textos que agora aqui se reproduz reflecte a abordagem muito pessoal que cada um dos intervenientes adoptou face ao seu entendimento do objecto e da ocasião. Com base na divisão de tarefas decidida ainda durante a reunião do júri, coube a Ana Pais assegurar a apresentação de Percursos, a Miguel-Pedro Quadrio o comentário de Circo e a mim próprio as apresentações de Vera San Payo de Lemos e de Francisco Leal.

É nossa convicção que esta nova modalidade de atribuição de prémios e, agora, a publicação do material crítico por eles suscitado preenchem, ainda que parcialmente, aquele que é o principal objectivo da nossa Associação: "Dignificar, estruturar e responsabilizar a actividade crítica relativa à teoria e prática do teatro, entendendo-se por actividade crítica não só a crítica de espectáculos, mas também tudo aquilo que diga respeito à informação, reflexão e teorização no campo das artes performativas". 

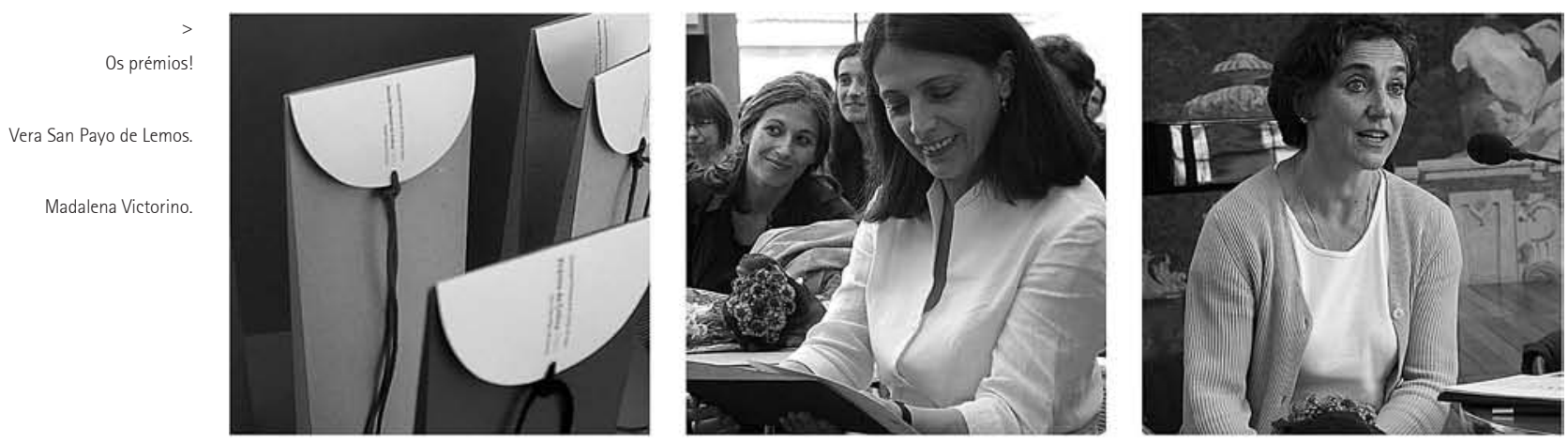

Maria Helena Serôdio e

Vera San Payo de Lemos.

0 Jardim de Inverno do Teatro Municipal de S. Luiz.
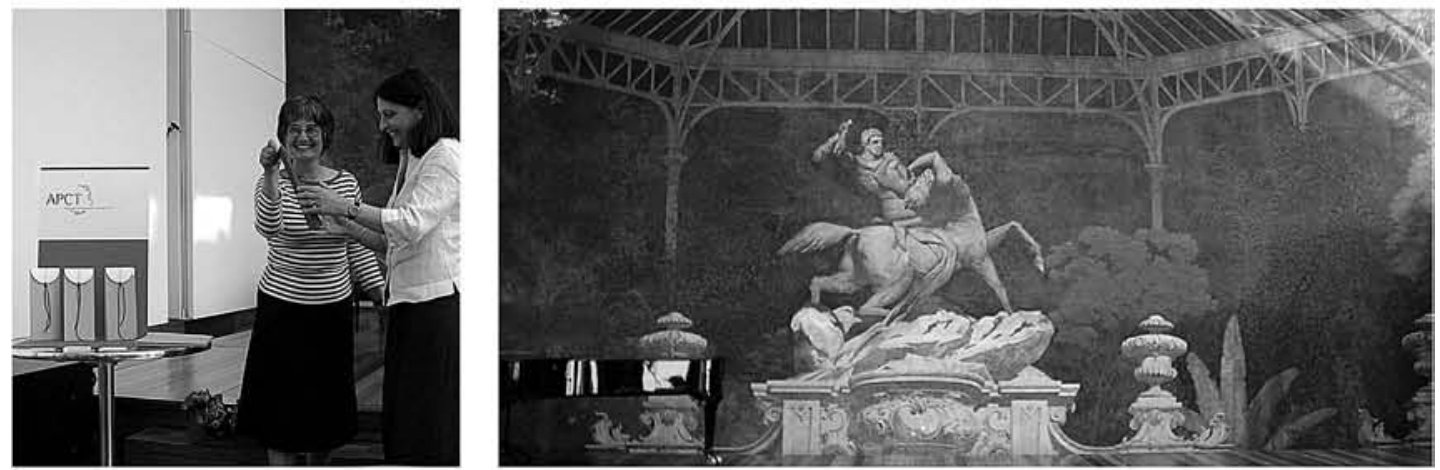

Mónica Guerreiro e

Miguel-Pedro Quadrio.

Carlos J. Pessoa e

Miguel-Pedro Quadrio.
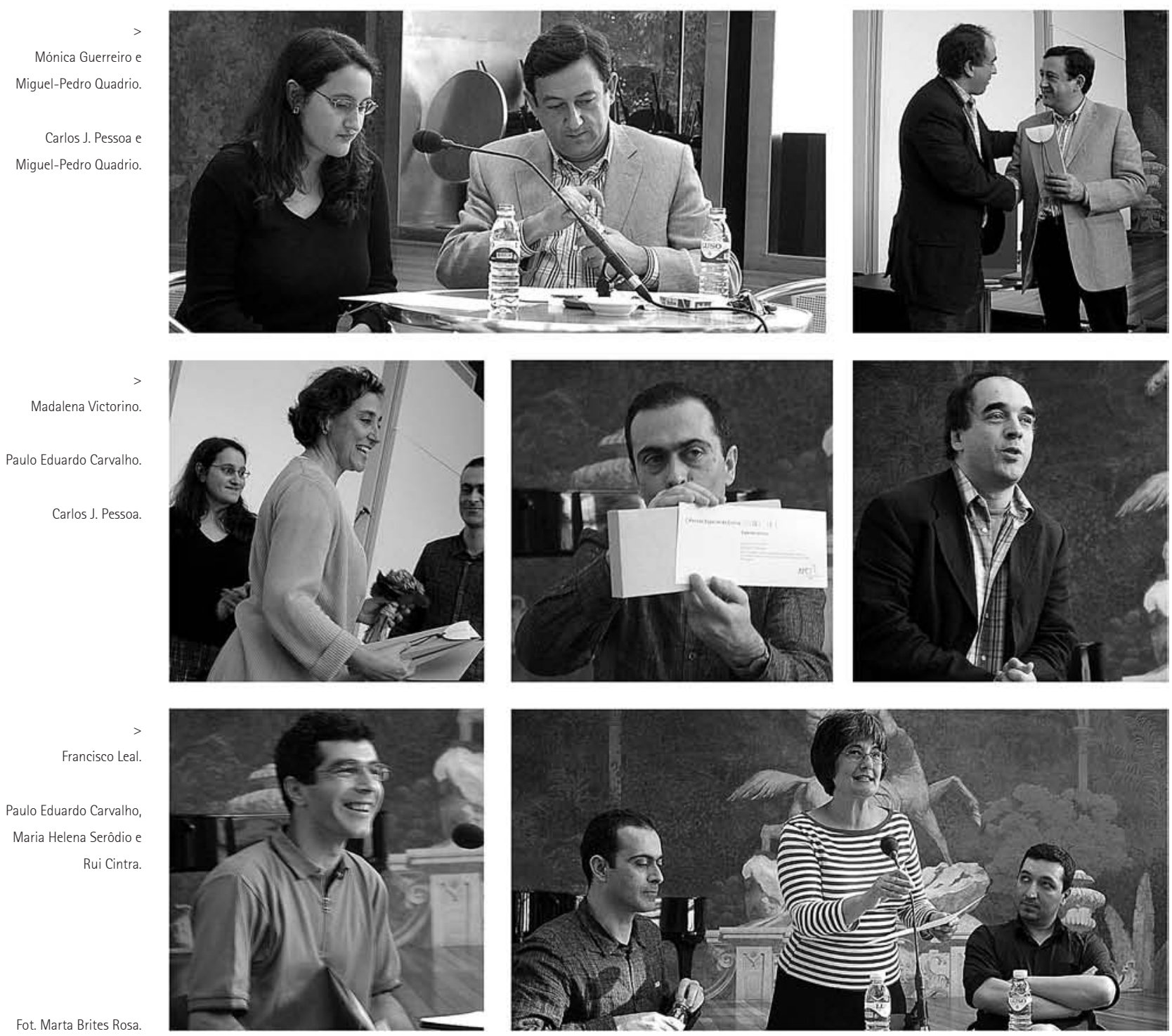

Fot. Marta Brites Rosa

Paulo Eduardo Carvalho,

Maria Helena Serôdio e

Rui Cintra. 